\title{
Pharmacokinetic-Pharmacodynamic Analysis of the Electrocardiographic Effects of Terfenadine and Quinidine in Rats
}

\author{
Hisakazu Ohtani, ${ }^{*}$ Erika Hanada, Koujirou Yamamoto, Yasufumi Sawada, ${ }^{1)}$ and \\ Tatsuji IGA \\ Department of Pharmacy, The University of Tokyo Hospital, Faculty of Medicine, The University of Tokyo, Hongo, \\ Bunkyo-ku, Tokyo 113, Japan. Received April 4, 1996; accepted June 3, 1996
}

\begin{abstract}
In establishing a method of electrocardiographic (ECG) measurement for investigating drug-induced ECG changes, we examined the ECG effects and pharmacokinetics of terfenadine (TFN) and quinidine (QND) in rats. The time profiles of the plasma concentration and ECG parameters, such as the QT interval determined from limb lead II (QT-II) and the precordial chest lead (QT-V), heart rate and PR interval, were examined during constant intravenous infusion of TFN (5 or $15 \mathrm{mg} / \mathrm{kg} / \mathrm{h}$ ) or QND sulfate dihydrate $(10$ or $30 \mathrm{mg} / \mathrm{kg} / \mathrm{h})$. Both agents provided significant and concentration-dependent QT prolongation. The plasma concentrations $\left(C_{10}\right)$, where $10 \mathrm{~ms}$ of QT prolongation was observed, were $1.03 \mu \mathrm{M}$ for TFN and $5.12 \mu \mathrm{M}$ for QND, respectively. The calculated plasma unbound concentration of $C_{10}\left(C_{10 \cdot \mathrm{f}}\right)$ was $10.3 \mathrm{nM}$ for TFN and 3.82 $\mu \mathrm{M}$ for QND, which coincides with previously reported in vitro values of $\mathrm{IC}_{50}$ for potassium channels. The drug-induced $\mathrm{QT}$ prolongation was quantitatively reproduced in rats within the clinical concentration range. The usefulness of our methodology for the evaluation of arrhythmogenic hazards of the drugs was also demonstrated.
\end{abstract}

Key words terfenadine; quinidine; electrocardiography; pharmacodynamics; QT interval

In recent years, many cases of drug-induced QT prolongation or "Torsades de Pointes" (TdP) have been reported, even with the use of non-cardiovascular drugs such as terfenadine $(\mathrm{TFN}){ }^{2,3)}$ astemizole,${ }^{4)}$ thioridazine, ${ }^{5)}$ chlorpromazine $^{6)}$ or erythromycin. ${ }^{7)}$ Clinical attention has especially been focused upon TFN, a non-sedating antihistamine. When orally administered, TFN undergoes first pass metabolism and is thoroughly converted into an active metabolite. ${ }^{8)}$ The parent TFN is thought to cause electrocardiographic (ECG) effects since the metabolite has much less electrophysiological potency. ${ }^{9,10)}$ TFN is rarely found (less than $5 \mathrm{ng} / \mathrm{ml}$ ) after an ordinary oral dosage regimen. ${ }^{8)}$ On the other hand, TFN is detected in high concentrations in cases of overdose ${ }^{2)}$ or with the co-administration of macrolide antibiotics ${ }^{11,12)}$ or azolerelated antifungals, ${ }^{13,14)}$ which lead to QT prolongation and TdP. ${ }^{2,3)}$

In evaluating the arrhythmogenic activity of a drug, investigation of a drug's influence upon the QT interval is essential since QT prolongation is employed as a clinical indicator in heralding arrhythmia, including TdP. ${ }^{15,16)}$ However, only a single report has referred to the relationship between the TFN concentration and QT prolongation in humans ${ }^{14)}$ and no further pharmacodynamic investigation has been reported.

Recently, in vitro techniques have been employed for preclinical electrophysiological studies. Here, parameters such as the prolongation of action potential duration (APD) or the inhibition of cardiac potassium currents served as indicators of clinical QT prolongation, where the QT interval is believed to reflect the APD ${ }^{17)}$ and is prolonged by the inhibition of the cardiac potassium channel. However, the relationship between APD prolongation in vitro and $\mathrm{QT}$ prolongation in vivo is not absolute. Wyse et al. reported the shortening of APD by the clinical range of quinidine (QND) using canine Purkinje fibers. ${ }^{18)}$ Thus, in vitro studies may contradict

* To whom correspondence should be addressed. the results of clinical observations, thereby necessitating an in vivo assessment of the ECG effects of drugs. In the past, canines or monkeys have been utilized to examine the ECG in preclinical studies. ECG assessment may be facilitated by the use of small animals such as rats. While Suzuki et al. reported the effects of antiarrhythmic agents based on the ECG in rats, no pharmacokinetic-pharmacodynamic analyses for ECG in small animals have been performed. ${ }^{19)}$

In this study we describe a method for ECG measurement in anesthetized rats and investigate the ECG effects of TFN and QND. Pharmacokinetic-pharmacodynamic analyses were carried out for each drug. Moreover, we compare the pharmacodynamic parameters with previously reported electrophysiological parameters in vitro and with clinical ECG properties.

\section{MATERIALS AND METHODS}

Chemicals Terfenadine and meclizine were kind gifts from Marion Merrell Dow K. K. (Osaka, Japan) and Pfizer Pharmaceuticals, Inc. (Tokyo, Japan), respectively. Quinidine sulfate dihydrate and quinine sulfate dihydrate were commercially purchased from Wako Pure Chemical Industries, Ltd. (Osaka, Japan). All other chemicals used were of reagent grade.

Recording of the ECG in Rats The schematic diagram for ECG recording in rats is displayed in Fig. 1A. Male Sprague-Dawley rats weighing $300-450 \mathrm{~g}$ were purchased from Nippon Seibutsu Zairyou Center and anesthetized with a combination of urethane and $\alpha$-chlorarose $(1.2 \mathrm{mg} / \mathrm{kg}$ and $30 \mathrm{mg} / \mathrm{kg}$ i.p., respectively). The precordial and limb hair were removed using a hair removing cream (Hair Remover, Kanebo, Tokyo). With the animals restrained in a supine position, the trachea, right jugular vein and right carotid artery were cannulated with polyethylene tubing. The body temperature was monitored

(C) 1996 Pharmaceutical Society of Japan 


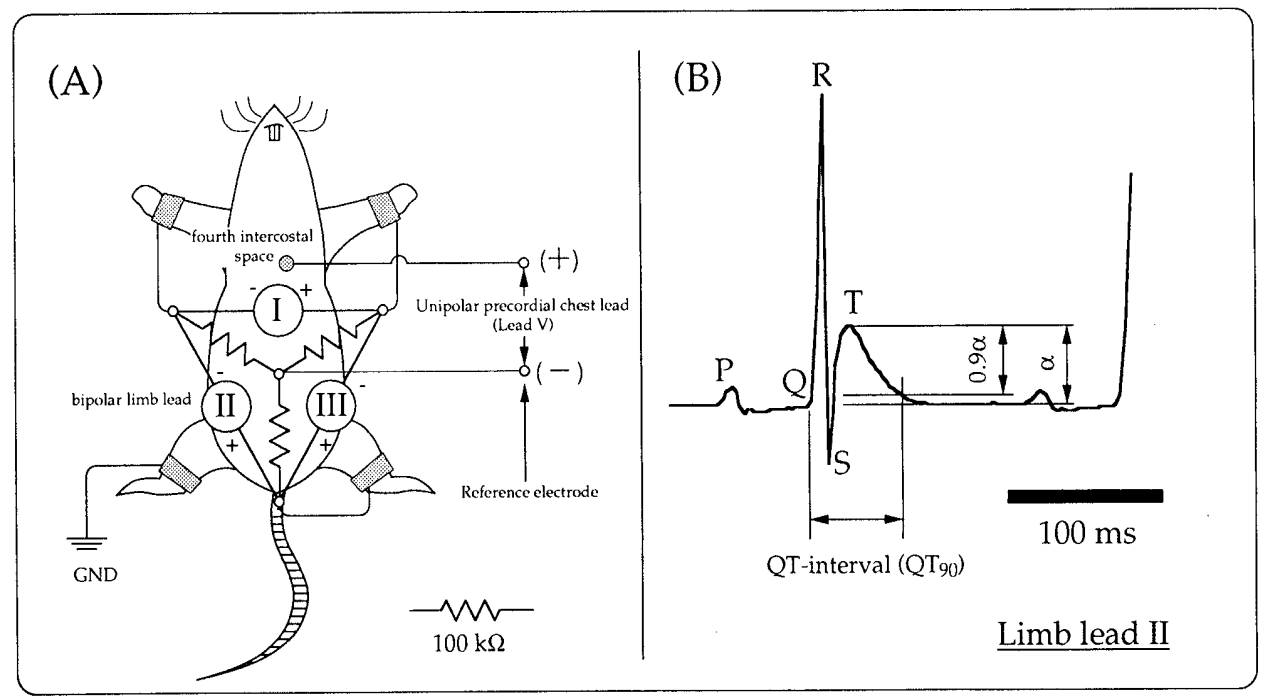

Fig. 1. (A) A Schematic Diagram for the Recording of Electrocardiograms in Rats

Copper plates, $1.0 \mathrm{~cm}$ in width, were attached to each limb as electrodes. The unipolar precordial chest lead (lead $\mathrm{V}$ ) was recorded as the potential from the reference electrode, the average potential of the left hindlimb and two forelimbs. The right hindlimb was connected to the ground. A stainless circular electrode (i.d. $=5.0 \mathrm{~mm}$ ) was attached at the fourth left intercostal space and served as the precordial electrode.

(B) A Typical Electrocardiogram Recorded from a Male Rat

The procedure for determining the OT intervals is also depicted. Noise may be eliminated by computing the mean values of the electrocardiographic data accumulated for $10 \mathrm{~s}$ by means of an A/D converter. The QT interval is defined as the interval between the start of the QRS complex and the end of the T wave, at which the amplitude of the $\mathrm{T}$ wave declined to $10 \%$ of its maximal.

by a rectal thermometer (MGA-210, Shibaura Electric, Tokyo) and maintained at $37.5 \pm 0.5^{\circ} \mathrm{C}$ throughout the experiment by means of a hot-water-circulating heat pad placed beneath the animals. Copper plate electrodes $(1.0 \mathrm{~cm}$ in width and $0.3 \mathrm{~mm}$ thick) were noninvasively fastened upon each limb. A stainless circular electrode (i.d. $=5 \mathrm{~mm}$ ) was attached by surgical tape on the anterior surface of the apex cordis, i.e. $1.0 \mathrm{~cm}$ left of the midline in the fourth intercostal area. Signals from the bipolar lead II and the unipolar precordial chest lead were amplified by means of an electric amplifier (AB-621G, Nihon-Kohden, Tokyo) and stored in a personal computer (PC-9801VX, NEC, Tokyo) via A/D converter (AnalogPro Jr., Canopus Electric, Kobe) at a sampling rate of $500 \mathrm{~Hz}$. The ECG parameters were calculated from the average wave shape computed from $10 \mathrm{~s}$ of recordings to eliminate noise. The QT interval was defined as the time from the start of the QRS complex to the end of the T wave, at which the amplitude of the $\mathrm{T}$ wave declines to $10 \%$ of its maximal (Fig. 1B). QT-II, defined as the QT interval from limb lead II, and QT-V, that from the precordial chest lead, were simultaneously analyzed.

Pharmacodynamic Experiments After stabilization of the ECG and body temperature, a physiological salt solution (PSS; $\mathrm{NaCl}: 135 \mathrm{~mm}, \mathrm{NaHCO}_{3}: 11.9 \mathrm{~mm}, \mathrm{KCl}$ : $5.4 \mathrm{mM}, \mathrm{CaCl}_{2}: 1.8 \mathrm{mM}, \mathrm{MgCl}_{2}: 1.0 \mathrm{~mm}$ ) was infused into the jugular vein at a rate of $2.32 \mathrm{ml} / \mathrm{h}$ for $10 \mathrm{~min}$. Next, TFN $(15$ or $5 \mathrm{mg} / \mathrm{kg} / \mathrm{h}$ ) or QND (30 or $10 \mathrm{mg} / \mathrm{kg} / \mathrm{h}$ as QND sulfate dihydrate) was infused by means of an infusion pump (Model 975, Harvard Apparatus, U.S.A.). QND and TFN were dissolved in a PSS, with TFN solubilized according to the method previously described by Webb et al. ${ }^{20)}$ Recordings of ECG were carried out prior to PSS administration, from 1 minute before to $24 \mathrm{~min}$ after the start of infusion, and at $30,40,50$, 60, 75 (QND only) and 90 min (QND only) post in- fusion.

Pharmacokinetic Study Pharmacokinetic studies were performed with different animals than those used in the pharmacodynamic experiment. All conditions were identical to the pharmacodynamic experiment, with the exception that blood samples of $250 \mu \mathrm{l}$ for TFN or $125 \mu \mathrm{l}$ for QND were collected at 2, 5, 10,20,30, and $60 \mathrm{~min}$ after the start of drug administration from the carotid artery. An additional $125 \mu \mathrm{l}$ of blood was collected at $90 \mathrm{~min}$ for QND. Blood samples were centrifuged to collect plasma and the drug concentration was determined by means of the procedure described below.

The conventional 2-compartment model, described in Eq. 1, was applied to analyze the time profile of QND concentration and to estimate the pharmacokinetic parameters. Parameters such as $V_{1}$ (distribution volume of the central compartment), $\alpha$ (elimination rate constant of the distribution phase), $\beta$ (elimination rate constant of the elimination phase) and $k_{10}$ (elimination rate constant from the central compartment) were estimated by means of simultaneous fitting of the data from two administration rates.

$$
C_{\mathrm{p}}=\frac{I}{V_{1} \cdot k_{10}}\left(1+\frac{\beta-k_{10}}{\alpha-\beta} \cdot e^{-\alpha \cdot t}+\frac{k_{10}-\alpha}{\alpha-\beta} \cdot e^{-\beta \cdot t}\right)
$$

where $I$ is the infusion rate and $C_{\mathrm{p}}$ represents the plasma drug concentration at time $t$.

For the pharmacokinetic analysis of TFN, 1-compartment model described in Eq. 2 was applied only for the slow infusion rate $(5 \mathrm{mg} / \mathrm{kg} / \mathrm{h})$ due to lack of linearity at a high dosage $(15 \mathrm{mg} / \mathrm{kg} / \mathrm{h})$.

$$
C_{\mathrm{p}}=\frac{\mathrm{I}}{V_{\mathrm{d}} \cdot k_{\mathrm{e}}}\left(1-e^{\left.-k_{\mathrm{e}} \cdot t\right)}\right.
$$

where $V_{\mathrm{d}}$ is the distribution volume and $k_{\mathrm{e}}$ is the elimination rate constant. 
Determination of TFN $100 \mu$ l of plasma was pipetted into a $10 \mathrm{ml}$ glass test tube, which was silicon-treated with Siliconize L-25 (Fuji Systems, Japan) and made alkaline with $100 \mu \mathrm{l}$ of $0.1 \mathrm{M} \mathrm{Na} \mathrm{NO}_{3}$. After the addition of an internal standard solution $(1.5 \mu \mathrm{g} / \mathrm{ml}$ of meclizine in isoamylalcohol) and $4.0 \mathrm{ml}$ of $n$-hexane, the samples were shaken using a reciprocal shaker for $10 \mathrm{~min}$ and then centrifuged at $1000 \times \boldsymbol{g}$ for $10 \mathrm{~min}$. The separated organic layer was initially evaporated using a rotary evaporator and then dried thoroughly under a gentle nitrogen stream in a warm water-bath $\left(45^{\circ} \mathrm{C}\right)$. The extract was dissolved in $50 \mu \mathrm{l}$ of the mobile phase, and $20 \mu \mathrm{l}$ was applied onto the HPLC system.

The HPLC system consisted of a liquid chromatograph LC 10AD (Shimadzu, Kyoto, Japan) with a UV detector SPD 10A (Shimadzu, Kyoto, Japan), with recording on the detection absorbance setting of $228 \mathrm{~nm}$. The chromatogram was recorded with a pen recorder (Model U-125S158, Shimadzu, Kyoto, Japan). The HPLC column $(250 \mathrm{~mm} \times 4.0 \mathrm{~mm}$ i.d.) was packed with $5 \mu \mathrm{m}$ cyano solid phase (Nucleosil $5 \mathrm{CN}$ ) and maintained at $50^{\circ} \mathrm{C}$. The mobile phase consisted of $12 \mathrm{~mm}$ potassium phosphate buffer (pH 3.5), methanol and acetonitrile $(53: 29: 18$, $\mathrm{v} / \mathrm{v}$ ), and was pumped at a flow rate of $2.0 \mathrm{ml} / \mathrm{min}$.

Determination of QND Plasma $(50 \mu \mathrm{l})$ was transferred into a glass test tube and spiked with $100 \mu$ l of internal standard solution $(1.0 \mu \mathrm{g} / \mathrm{ml}$ quinine sulfate dihydrogen solution in $0.1 \mathrm{M} \mathrm{Na}_{2} \mathrm{CO}_{3}$ ). The sample was extracted with $4.0 \mathrm{ml}$ of dichloromethane using a reciprocal shaker for $10 \mathrm{~min}$. The organic phase was separated by centrifugation at $1000 \times \boldsymbol{g}$ for $10 \mathrm{~min}$ and evaporated by a rotary evaporator. The extract was reconstituted in $50 \mu \mathrm{l}$ of mobile phase, and $20 \mu \mathrm{l}$ was applied to the HPLC system.

The column used for chromatographic separation was a Cosmosil packed column 5C18P (Nacalai Tesque, Inc.; $15 \mathrm{~cm} \times 4.7 \mathrm{~mm}$ i.d.) which was placed at room temperature. The mobile phase consisted of $0.3 \%$ triethylaminephosphate buffer $(\mathrm{pH} \mathrm{3.0)}$ and acetonitrile $(85: 15, \mathrm{v} / \mathrm{v})$, and was pumped at a rate of $1.5 \mathrm{ml} / \mathrm{min}$. The detection absorbance was set at $254 \mathrm{~nm}$.

Pharmacokinetic-Pharmacodynamic Analysis of QT Prolongation The ECG effects of TFN and QND on the QT interval were analyzed from both a pharmacokinetic and pharmacodynamic perspective. The effects of a drug $(E)$ at each time were expressed as the deviation from the value prior to drug administration. The plasma concentration of a drug $\left(C_{\mathrm{p}}\right)$ at each time was estimated by linear interpolation of the pharmacokinetic data.

The effect compartment model ${ }^{21)}$ was applied for the pharmacodynamic analysis of TFN because a delay of QT prolongation was observed. The drug concentration in the effect compartment $\left(C_{\mathrm{e}}\right)$ is described by Eq. 3 .

$$
\frac{\mathrm{d} C_{\mathrm{e}}}{\mathrm{dt}}=k_{\mathrm{co}}\left(C_{\mathrm{p}}-C_{\mathrm{e}}\right)
$$

where $k_{\mathrm{e} 0}$ is the elimination rate constant from the effect compartment. The $E_{\max }$ model described in Eq. 4 was employed to relate the $C_{\mathrm{e}}$ to the effects $(E)$, because the saturation of $E$ against $C_{\mathrm{e}}$ was observed.

$$
E=\frac{E_{\max } \cdot C_{\mathrm{e}}}{\mathrm{EC}_{50}+C_{\mathrm{e}}}
$$

where $E_{\max }$ and $\mathrm{EC}_{50}$ represent the maximum effects and the concentration that gives half-maximal effects, respectively.

Differentiation of Eq. 4 gives Eq. $4^{\prime}$.

$$
\frac{\mathrm{d} E}{\mathrm{~d} t}=\frac{\mathrm{EC}_{50} \cdot E_{\max }}{\left(\mathrm{EC}_{50}+C_{\mathrm{e}}\right)^{2}} \cdot \frac{\mathrm{d} C_{\mathrm{e}}}{\mathrm{d} t}
$$

Eqs. 3 and $4^{\prime}$ make Eq. 5.

$$
\frac{\mathrm{d} E}{\mathrm{~d} t}=k_{\mathrm{e} 0} \cdot\left(E_{\max }-E\right) \cdot \frac{C_{\mathrm{p}} \cdot E_{\max }-C_{\mathrm{p}} \cdot E-E \cdot \mathrm{EC}_{50}}{E_{\max } \cdot \mathrm{EC}_{50}}
$$

The pharmacodynamic parameters, $E_{\max }, \mathrm{EC}_{50}$ and $k_{\mathrm{e} 0}$, were calculated by the simultaneous fitting of $E$ and $C_{\mathrm{p}}$ at all infusion rates, to Eq. 5 using a non-linear least-squares program (MULTI(RUNGE)) with a modified Marquardt method without weighing. ${ }^{22)}$

For the analysis of quinidine, a linear relationship between $E$ and $C_{\mathrm{p}}$ was assumed, and Eq. 6 was proposed, due to the inability of the $E_{\max }$ model to describe this relationship.

$$
E=K \cdot C_{\mathrm{p}}
$$

where $K$ is the slope, i.e. one of the indicators for potency.

The potency of TFN or QND for QT prolongation was represented by the concentration " $C_{10}$," where $10 \mathrm{~ms}$ of QT prolongation was evoked. It was theoretically determined by applying Eq. 5 or 6 . Furthermore, the unbound drug concentration at $C_{10}, \mathrm{C}_{10 \cdot \mathrm{f}}$, was estimated by the plasma protein binding ratio $\left(99.0 \%\right.$ for $\mathrm{TFN}^{23)}: 66.8 \%$ for $\mathrm{QND}^{24)}$ ).

\section{RESULTS}

Measurement of ECG Figure 2 represents a typical ECG of a rat recorded in this study. The heart rate, QT interval from lead II (QT-II), QT interval from precordial chest lead (QT-V) and PR interval were $331.7 \pm 34.7$ $\mathrm{min}^{-1}, 63.4 \pm 6.4 \mathrm{~ms}, 62.2 \pm 7.1 \mathrm{~ms}$ and $59.8 \pm 4.0 \mathrm{~ms}$, respectively (mean \pm S.D. from $23-24$ animals).

Effects of TFN on ECG A significant, dose-dependent increase in QT interval coinciding with the change in ECG shape was observed during the constant intravenous infusion of TFN ( Fig. 2A, Figs. 3A, B). A time-dependent decrease in heart rate was observed and it paralleled the increase in $\mathrm{PR}$ interval at a high administration rate $(15 \mathrm{mg} / \mathrm{kg} / \mathrm{h})($ Figs. 3C, D).

Supraventricular arrhythmia was observed in two of four rats administered high doses of TFN (Fig. 4). The disappearance of the $\mathrm{P}$ wave and the alteration of the RR interval, which may indicate an abnormality of the SA node, made the estimation of the ECG parameters impossible. Moreover, one of four animals died after $55 \mathrm{~min}$, most likely due to sinus arrest, during the pharmacodynamic study.

Effects of QND on ECG As observed for TFN, a significant, dose-dependent increase in QT interval was also observed for QND ( Fig. 2B, Figs. 5A, B). Unlike $\mathrm{TFN}$, a decrease in heart rate and the prolongation of the 

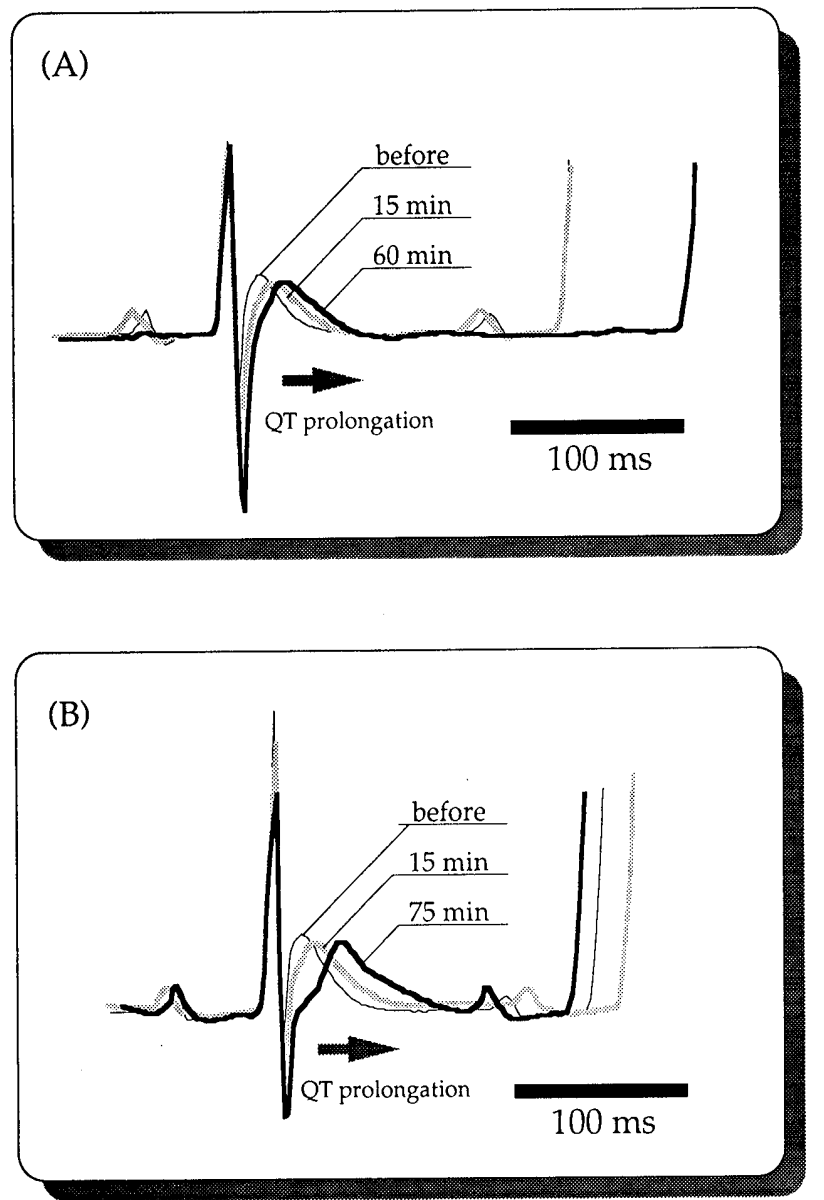

Fig. 2. Electrocardiographic Changes Resulting from the Constant Infusion of (A) Terfenadine $\left(15 \mathrm{mg} / \mathrm{kg} / \mathrm{h}\right.$ ) or (B) Quinidine Sulfate $\cdot 2 \mathrm{H}_{2} \mathrm{O}$ $(30 \mathrm{mg} / \mathrm{kg} / \mathrm{h})$

The waves prior to drug administration, and 15 and $60 \mathrm{~min}$ ( $75 \mathrm{~min}$ for quinidine) post drug infusion are shown.
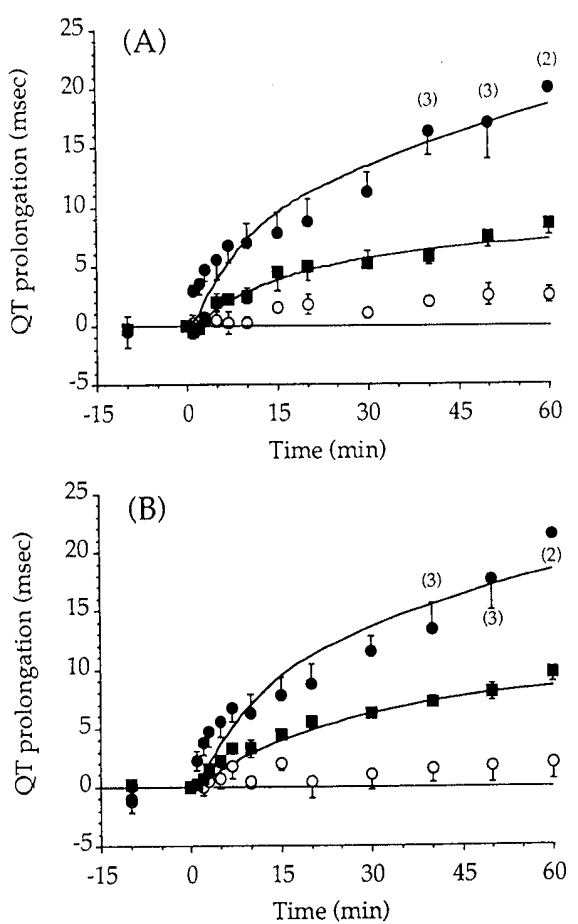

PR interval were rather weak in comparison to the effects on the QT interval (Figs. 5C, D). That is, QND provided only a slight and insignificant effect on the heart rate or PR interval, even at a high concentration, where QND increased the QT interval more than TFN did.

Pharmacokinetics of TFN The time profile of the TFN concentration in plasma is shown in Fig. 6A. At the low dose $(5 \mathrm{mg} / \mathrm{kg} / \mathrm{h})$ of TFN, steady state was rapidly achieved and the time profile satisfies the 1-compartment model (Eq. 2) . The distribution volume $\left(V_{\mathrm{d}}\right)$ and half-life $\left(t_{1 / 2}\right)$ were $580 \mathrm{ml} / \mathrm{kg}$ and $1.1 \mathrm{~min}$, respectively. At the high dose $(15 \mathrm{mg} / \mathrm{kg} / \mathrm{h})$, the plasma concentration of TFN still increased at $60 \mathrm{~min}$.

Pharmacokinetics of QND The time profile of the QND concentration in plasma is shown in Fig. 6B and satisfies the 2-compartment model (Eq. 1). The half-life of the terminal phase $\left(t_{1 / 2}\right)$, distribution volume at steady state $\left(V_{\mathrm{dss}}\right)$ and the total clearance were $49 \mathrm{~min}, 188 \mathrm{ml} / \mathrm{kg}$ and $72.5 \mathrm{ml} / \mathrm{min} / \mathrm{kg}$, respectively. At the high dose $(30 \mathrm{mg} / \mathrm{kg} / \mathrm{h}$ ), the plasma concentration of TFN still increased at $90 \mathrm{~min}$.

Pharmacokinetic-Pharmacodynamic Analysis of QT Prolongation The relationship between plasma TFN concentration and the change in QT interval is shown in Fig. 7.

Pharmacodynamic parameters were estimated from the pharmacokinetic-pharmacodynamic analysis applying each model described in the "method" section and are shown in Table 1. The parameters for TFN, such as $E_{\max }$, $\mathrm{EC}_{50}$ or $k_{\mathrm{e} 0}$ from QT-II, were virtually identical to those from QT-V. For QND, the potency $(K)$ calculated from QT-II and QT-V were $1.95 \mathrm{~ms} / \mu \mathrm{M}$ and $1.75 \mathrm{~ms} / \mu \mathrm{M}$, respectively. The $\mathrm{C}_{10 \text {.f }}$ of TFN and QND from QT-II were $8.22 \mathrm{~nm}$ and $3.82 \mu \mathrm{M}$, respectively.
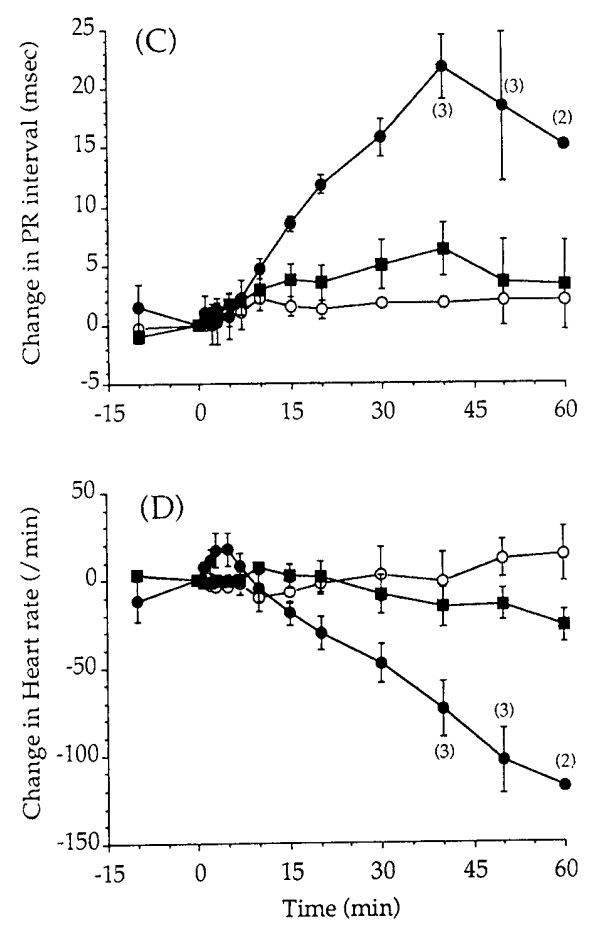

Fig. 3. Time Courses of Electrocardiographic Effects Resulting from the Constant Intravenous Infusion of Terfenadine

(A) Change in QT interval recorded from lead II; (B) change in QT interval from the chest lead; (C) change in PR interval; (D) change in heart rate. The lines in panels (A) and (B) are the simulation curves calculated from the parameters in Table $1 . O$, control; $\mathbf{\square}, 5 \mathrm{mg} / \mathrm{kg} / \mathrm{h} ; \boldsymbol{\bullet}, 15 \mathrm{mg} / \mathrm{kg} / \mathrm{h}$. ( $(n=4$ if not indicated in parenthesis, mean \pm S.E.M.) 
Lead II

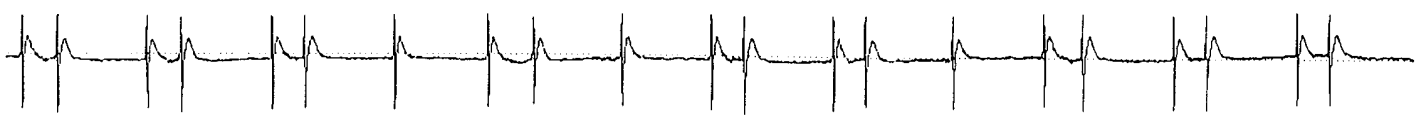

Lead V

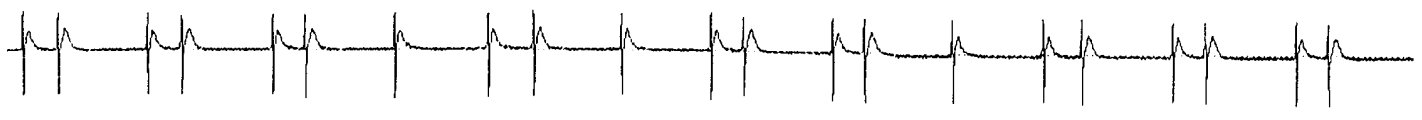

$800 \mathrm{msec}$

Fig. 4. Supraventricular Arrhythmia Observed at $60 \mathrm{~min}$ Post Constant Intravenous Infusion of Terfenadine $(15 \mathrm{mg} / \mathrm{kg} / \mathrm{h})$

The disappearance of the $\mathrm{P}$ wave and the alteration of the RR interval may indicate an abnormality of the sinoatrial (SA) node.
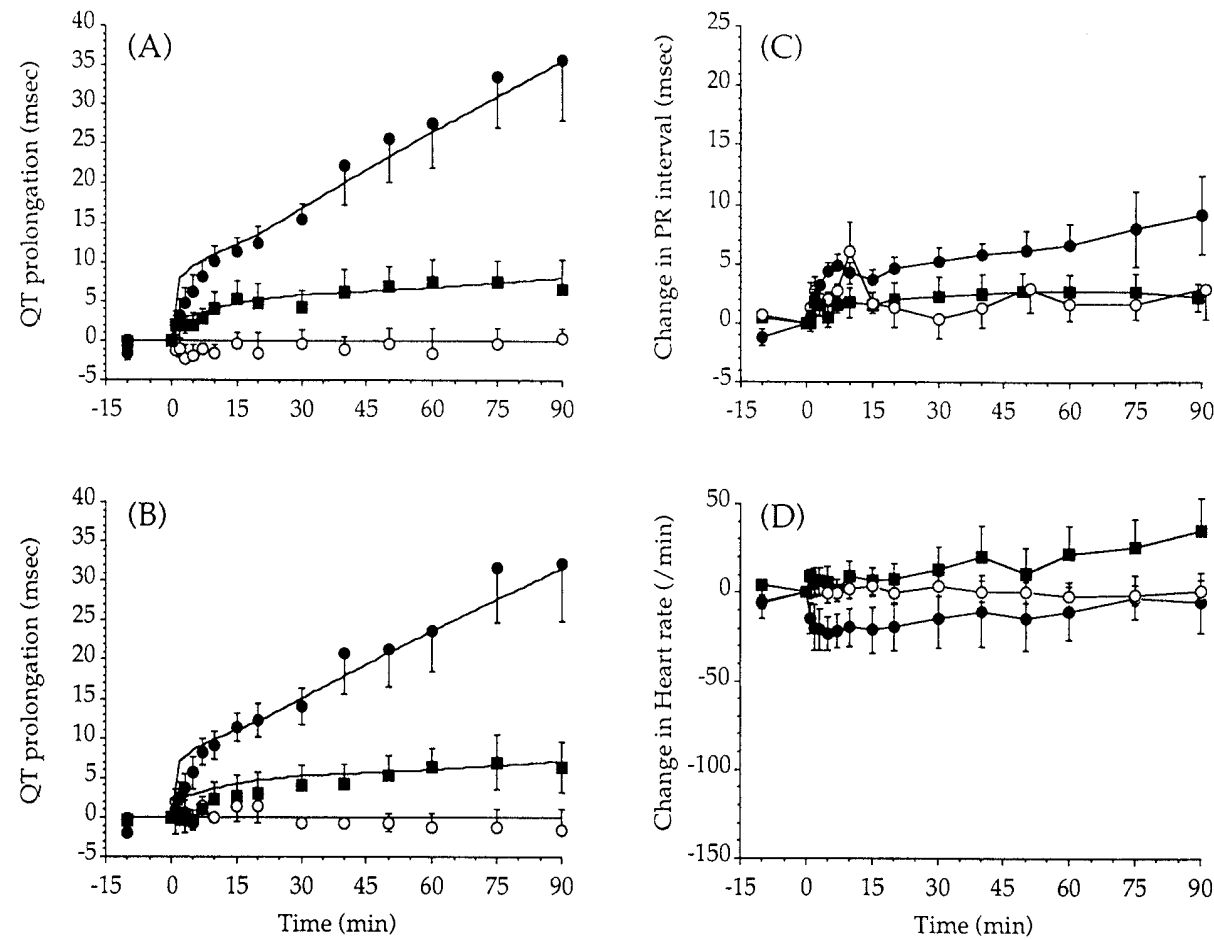

Fig. 5. Time Profiles of Electrocardiographic Effects Resulting from the Constant Intravenous Infusion of Quinidine Sulfate Dihydrate

(A) Change in QT interval recorded from lead II; (B) change in QT interval from the chest lead; (C) change in PR interval; (D) change in heart rate. The lines in panel (A) and (B) are the simulation curves calculated from the parameters in Table $1 . O$, control; $\mathbf{\square}, 10 \mathrm{mg} / \mathrm{kg} / \mathrm{h} ; \mathbf{0}, 30 \mathrm{mg} / \mathrm{kg} / \mathrm{h}$. $(n=3-5$, mean \pm S.E.M.).

\section{DISCUSSION}

In this study, the ECG in rats was recorded to quantitatively evaluate a drug-induced ECG disturbance which is clinically observed in humans. The ECG in rats may be more easily investigated than in other animals such as canines or monkeys. Some reports refer to the methodology and characteristics of ECG in rats. Suzuki et al. investigated the effects of antiarrhythmic drugs of class Ia, Ib, II and IV on the ECG of Wistar rats. ${ }^{19}$ However, the relationship between the plasma drug concentration and the effects of drugs on ECG in rats has not been precisely analyzed. The procedure in this animal study may serve as a model for the pharmacokineticpharmacodynamic evaluation of the clinical risks of drug-induced ECG disturbance.
Plasma electrolytes, especially potassium, play an important role in arrhythmogenicity. ${ }^{25,26)}$ Based on our preliminary experiments (data not shown), where the continuous infusion of saline decreased the plasma potassium, PSS was utilized as a vehicle which had no effect on the ECG parameters.

For evaluating the QT interval, correction of the heart rate is significant. "Bazett's formula" ${ }^{27)}$ has been widely used for the correction of the QT interval at the clinical stage. However, Bazett's formula may not be directly applied to the rat ECG since it is based upon human ECG, which questions the comparison with the linear correlation. ${ }^{28)}$ Moreover, the actual QT interval rather than the QTc may be more preferable in indicating TdP. ${ }^{29)}$ Therefore, the actual QT interval without any correction with heart rate was used here. 
TFN and QND evoked a prominent prolongation of the QT interval on rats in vivo, and their $C_{10}$ s were $0.597-0.822 \mu \mathrm{M}$ and $5.12-5.73 \mu \mathrm{M}$, respectively. The plasma concentration of drugs observed in clinical cases of TdP was $0.0912-0.121 \mu \mathrm{M}$ for $\mathrm{TFN}^{2,3)}$ and $3.70-$ $34.2 \mu \mathrm{M}$ for QND, ${ }^{30)}$ respectively. For QND, the $C_{10}$ falls within the range of the plasma concentration at the event of TdP. Although the $C_{10}$ for TFN is also comparable to the concentration at $\mathrm{TdP}$, some divergence was observed. The preferable explanation for this occurrence is that the plasma TFN concentration reported in the cases
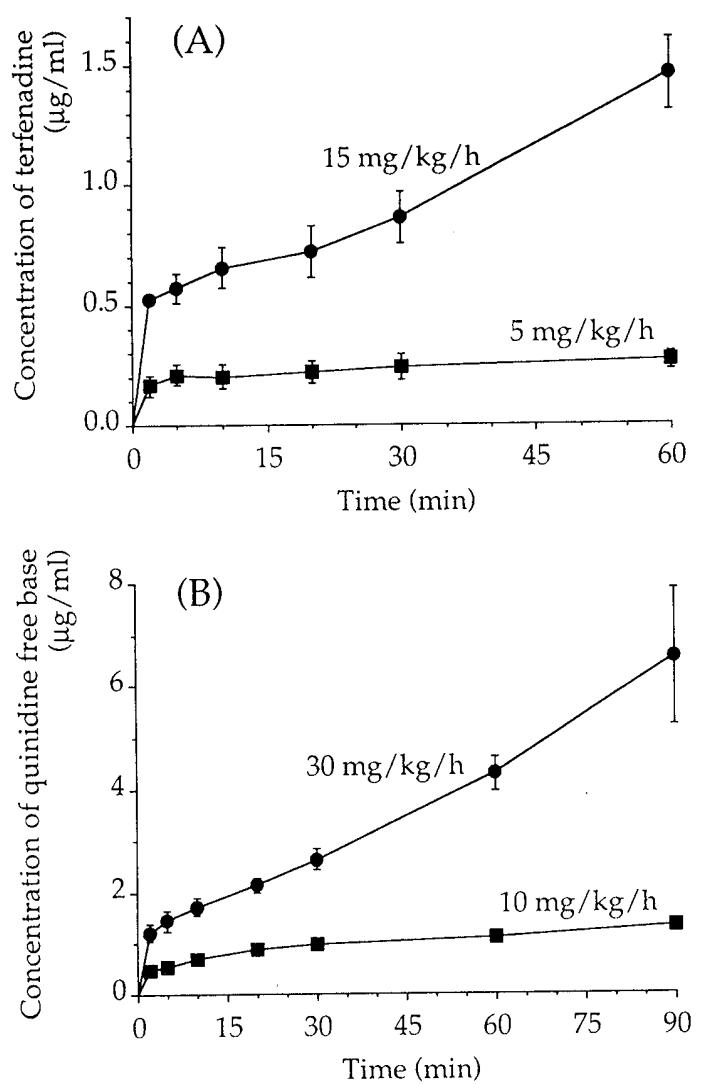

Fig. 6. Time Course of the Plasma Concentration of (A) Terfenadine and (B) Quinidine (Shown as Free Base)

- $5 \mathrm{mg} / \mathrm{kg} / \mathrm{h}$ for terfenadine and $10 \mathrm{mg} / \mathrm{kg} / \mathrm{h}$ for quinidine sulfate dihydrate; - $15 \mathrm{mg} / \mathrm{kg} / \mathrm{h}$ for terfenadine and $30 \mathrm{mg} / \mathrm{kg} / \mathrm{h}$ for quinidine sulfate dihydrate $(n=3-4$, mean \pm S.E.M. $)$.

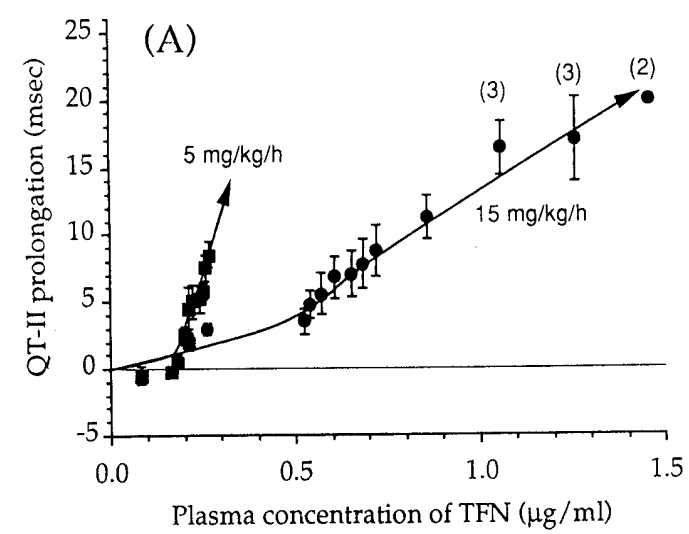

of TdP is not assayed using plasma during the event, but using that which has been collected at hospital admission. The plasma TFN may decline at the time of admission due to its rapid elimination.

A higher drug concentration was required to exhibit effects on the PR interval and heart rate, and such effects may result from mechanism other than that which induces QT prolongation. In fact, a PR interval that reflects atrioventricular conduction velocity is prolonged as a result of a cardiac sodium channel blockade. ${ }^{30)}$ Here, QT prolongation may result from the inhibition of the potassium channel, which is associated with the repolarization of the cardiac myocytes. ${ }^{31)}$

Cardiac potassium channels are classified as delayed rectifier potassium channels $\left(\mathrm{I}_{\mathrm{K}}\right)$, inwardly rectifying potassium channels $\left(I_{K 1}\right)$, transient outward potassium channels $\left(\mathrm{I}_{\mathrm{TO}}\right.$ ) and ATP dependent potassium channels $\left(\mathrm{I}_{\mathrm{K} \cdot \mathrm{ATP}}\right)$, and all are assumed to be targets of antiarrhythmic agents. ${ }^{32)} \mathrm{I}_{\mathrm{K}}$ is divided into two classes, i.e. a rapidly activating component $\left(\mathrm{I}_{\mathrm{K}_{\mathrm{r}}}\right)$ and a slowly activating component $\left(\mathrm{I}_{\mathrm{Ks}}\right) \cdot{ }^{33)}$ From previous work on the administration of blockers selective for each type of potassium channel in animals, the blockade of at least three types of potassium channels, i.e. $\mathrm{I}_{\mathrm{K}}, \mathrm{I}_{\mathrm{TO}}$ and $\mathrm{I}_{\mathrm{K} 1}$, induces QT prolongation on ECG. ${ }^{34-36)}$

Table 1. Pharmacodynamic Parameters of QT Prolongation of Terfenadine and Quinidine in Rats in Vivo

\begin{tabular}{lcccc}
\hline \hline Parameters & Lead & \multicolumn{2}{c}{ Terfenadine } & Quinidine \\
\hline$E_{\max }(\mathrm{ms})$ & Limb (II) & 33.0 & \pm 5.9 & - \\
& Chest (V) & 28.1 & \pm 4.2 & \\
$\mathrm{EC}_{50}(\mu \mathrm{M})$ & Limb (II) & $1.890 \pm 0.733$ & - \\
& Chest (V) & $1.081 \pm 0.505$ & \\
$k_{\mathrm{e} 0}\left(\mathrm{~min}^{-1}\right)$ & Limb (II) & $0.0619 \pm 0.0208$ & - \\
& Chest (V) & $0.0382 \pm 0.0177$ & 1.95 \\
$K(\mathrm{~ms} / \mu \mathrm{M})$ & Limb (II) & - & 1.75 \\
& Chest (V) & 0.822 & 5.12 \\
$C_{10}(\mu \mathrm{M})$ & Limb (II) & 0.597 & 5.73 \\
& Chest (V) & 8.22 & 3820 \\
$C_{10}(\mathrm{f} \mathrm{nM})$ & Limb (II) & 5.97 & 3420 \\
& Chest (V) & & \\
\hline
\end{tabular}

(mean \pm S.D.).

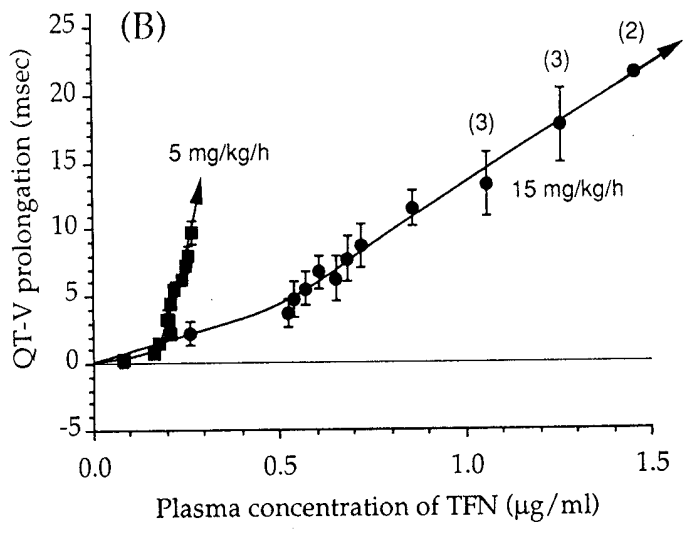

Fig. 7. The Relationship between the Plasma TFN Concentration and the Change in QT-II (Panel (A)) or QT-V (Panel (B)) Interval at an Administration Rate of 5 or $15 \mathrm{mg} / \mathrm{kg} / \mathrm{h}$

The plasma TFN concentration at each time was estimated by the linear interpolation of the pharmacokinetic data. Each arrow indicates an elapse of time. $(n=4$ if not indicated in parenthesis, mean \pm S.E.M.). 
Table 2. Comparison of Pharmacodynamic Parameters for QT Prolongation in Vivo and Electrophysiological Parameters in Vitro

\begin{tabular}{lcrcc}
\hline \hline & $\begin{array}{c}C_{10 \cdot \mathrm{f}} \\
(\mathrm{nM})\end{array}$ & $\begin{array}{c}\mathrm{IC}_{50} \text { for } \mathrm{I}_{\mathrm{k}} \\
(\mathrm{nM})\end{array}$ & $\begin{array}{c}\mathrm{IC}_{50} \text { for } \mathrm{I}_{\mathrm{TO}} \\
(\mathrm{nM})\end{array}$ & $\begin{array}{c}E_{\max } \\
(\mathrm{ms})\end{array}$ \\
\hline $\begin{array}{l}\text { Terfenadine } \\
\text { Quinidine }\end{array}$ & $\begin{array}{c}5.97--8.22^{d)} \\
3420-3820^{d)}\end{array}$ & $\begin{array}{r}50^{a, d)} \\
14300^{(, d)}\end{array}$ & $\begin{array}{c}>1000^{b} \\
\left.3900^{c, d}\right)\end{array}$ & $\begin{array}{c}28.1-33.0 \\
\text { Not determined }\end{array}$ \\
\hline
\end{tabular}

a) Ref. 37. b) Ref. 38. c) Ref. 39. d) Within the concentration range of our present study.

TFN at $50 \mathrm{~nm}$ or $10 \mathrm{~nm}$ was reported to provide about $50 \%$ or $30 \%$ inhibition of $\mathrm{I}_{\mathrm{Kr}}$ on isolated guinea pig myocytes, respectively. ${ }^{37)}$ Thus, the concentration $C_{10 \cdot f}$ $(5.97-8.22 \mathrm{~nm})$ is essentially identical to the in vitro inhibitory potency of $\mathrm{I}_{\mathrm{Kr}}$. On the other hand, a higher concentration $(1 \mu \mathrm{M})$ of TFN inhibits only $15 \%$ of $\mathrm{I}_{\mathrm{TO}} \cdot{ }^{38)}$ In this study, QT prolongation induced by TFN may predominantly result from the inhibition of $\mathrm{I}_{\mathrm{K}}$.

In addition, QND is known to inhibit potassium channels, and its $\mathrm{IC}_{50}$ s for $\mathrm{I}_{\mathrm{TO}}$ and $\mathrm{I}_{\mathrm{K}}$ are $3.9 \mu \mathrm{M}$ and $14.3 \mu \mathrm{M}$, respectively. The QT prolongation observed at the clinical therapeutic concentration is assumed to result from the blockade of $\mathrm{I}_{\mathrm{TO}} \cdot{ }^{39)}$ However, the $\mathrm{IC}_{50} \mathrm{~s}$ for $\mathrm{I}_{\mathrm{TO}}$ and $\mathrm{I}_{\mathrm{K}}$ are comparable, and both potassium channels may be blocked within the range of QND concentration in our study. Hence, it may be that an $\mathrm{I}_{\mathrm{TO}^{-}}$-dependent QT prolongation was observed at a low concentration of $\mathrm{QND}$, and an $\mathrm{I}_{\mathrm{K}}$-dependent component of QT prolongation was observed under a high concentration of QND. The above assumption may explain the fact that the sigmoid $E_{\max }$ model (Eq. 4) could not adequately explain the QT prolongation induced by QND. Thus, the in vitro investigation of only one type of potassium channel may not sufficiently explain the QT prolongation observed in vivo.

In this study, the $C_{10 \cdot \mathrm{f}}$ values $(5.97-8.22 \mathrm{~nm}$ for TFN and 3.42-3.82 $\mu \mathrm{M}$ for QND) coincide well with the in vitro inhibitory potency for $\mathrm{I}_{\mathrm{K}}$ or $\mathrm{I}_{\mathrm{TO}}$, and greater QT prolongation was observed in the presence of a high concentration of QND, which blocks both $\mathrm{I}_{\mathrm{K}}$ and $\mathrm{I}_{\mathrm{TO}}$ (Table 2). Since the results of our study correlate well with clinical ECG properties and with in vitro examinations, this methodology may be useful in evaluating the relationship between in vitro electrophysiological studies and the clinical aspects of QT prolongation.

The parent TFN was rapidly eliminated with a half-life of $1.1 \mathrm{~min}$, which is in accordance with the fact that TFN is extensively metabolized in liver. ${ }^{8,40)}$ Distinct non-linear kinetics were observed at the high administration rate $(15 \mathrm{mg} / \mathrm{kg} / \mathrm{h})$ of TFN. The reduction in the clearance may result from a decrease in the hepatic blood flow, followed by bradycardia. Because of this non-linear property at a high concentration, it was difficult to attain a steady state or stable kinetics of TFN. Therefore, we did not perform pharmacokinetic-pharmacodynamic analysis on the steady state at a high infusion rate or post-infusion. We did not refer to the metabolite of TFN because it had no significant effect on the cardiac potassium channel and is not considered to be a cause of QT prolongation or TdP. ${ }^{9,10)}$

The kinetics of QND was essentially described by the 2-compartment model in Eq. 1, and the half-life of the $\beta$ phase was $49 \mathrm{~min}$, which is identical to the value reported by Sugihara et al. ${ }^{23)}$ A slight residual deviation was observed when the concentration of QND was quite high, resulting from the decrease in hepatic extraction ratio in accordance with an increase in QND concentration, reported by Sugihara et al. ${ }^{23)}$

We employed the effect compartment model for the evaluation of TFN-induced QT prolongation, since a greater delay of QT prolongation was observed at the higher infusion rate $(15 \mathrm{mg} / \mathrm{kg} / \mathrm{h})$ compared with the lower infusion rate $(5 \mathrm{mg} / \mathrm{kg} / \mathrm{h})$ (Fig. 7). However, this delay was not observed in the case of QND. Although the factor of this difference in unclear, the pharmacokinetic properties of each drug may contribute in part because the mechanism of the action of these agents is essentially identical (i.e. inhibition of the potassium channel).

As our pharmacokinetic-pharmacodynamic methodology might be applicable for evaluation of the arrhythmogenic hazards of drugs other than QND or TFN, further investigation on other drugs should be carried out.

In conclusion, utilizing rat ECG, the clinically-observed QT prolongation induced by TFN and QND was reproduced. In addition, the concentration $C_{10}$ correlated well with the plasma concentration, where QT prolongation or $\mathrm{TdP}$ were clinically observed. Moreover, the concentration $C_{10 \cdot \mathrm{f}}$ was virtually identical to the inhibitory potency for $\mathrm{I}_{\mathrm{K}}$ or $\mathrm{I}_{\mathrm{TO}}$ reported in vitro. These results indicate that the methodology in our present study may serve as a means of evaluating the risk of drug-induced arrhythmia.

\section{REFERENCES}

1) Present address: Faculty of Pharmaceutical Sciences, Kyushu University, Maidashi, Fukuoka 812, Japan.

2) Davies A. J., Hatindra V., McEwan A., Ghose R. R., Br. Med. J., 298, 325 (1989).

3) Monahan B. P., Ferguson C. L., Killeavy E. S., Lioyd B. K., Troy J., Cantilena L. R., Jr., J. Am. Med. Assoc., 264, 2788-2790 (1990).

4) Craft T. M., Br. Med. J., 292, 660 (1986).

5) Kemper A. J., Dunlap R., Pietro D. A., J. Am. Med. Assoc., 249, $2931-2934$ (1983).

6) Johan A., Chia B. L., Nadarajah K., Singapore Med. J., 24, $110-113(1982)$

7) Gitler B., Berger L. S., Buffa S. D., Chest, 105, 368-372 (1994).

8) Garteiz D. A., Hook R. H., Walker B. J., Okerholm R. A., Arzneim.-Forsch./Drug Res., 32, 1185 -1190 (1982).

9) Woosley R. L., Chen Y., Freiman J. P., Gillis R. A., J. Am. Med. Assoc., 269, $1532-1536$ (1993).

10) Rampe D., Wible B., Brown A. M., Dage R. C., Mol. Pharmacol., 44, 1240-1245 (1993).

11) Honig P. K., Woosley R. L., Zamaki K., Conner D. P., Cantilena L. R., Clin. Pharmacol. Ther., 52, 231-238 (1992).

12) Honig P. K., Wortham D. C., Zamaki K., Cantilena R., Drug Invest., 7, 148-156 (1994).

13) Honig P. K., Wortham D. C., Zamaki K., Mullin J. C., Conner D. P., Cantilena L. R., Clin. Pharmacol. Ther., 53, 630-636(1993).

14) Honig P. K., Wortham D. C., Zamaki K., Mullin J. C., Conner D. P., Cantilena L. R., J. Am. Med. Assoc., 269, 1513-1518(1993).

15) Woosley R. L., Sale M., Am. J. Cardiol., 72, 36B-43B (1993).

16) Lipicky E. J., Am. J. Cardiol., 72, 53B-_54B (1993).

17) Zaza A., Malfatti G., Schwartz P. J., Circ. Res., 68, 1191-1203 (1991).

18) Wyse K. R., Ye V., Campbell T. J., J. Cardiovasc. Pharmacol., 21, $316-322$ (1993) 
19) Suzuki J., Tsubone H., Sugano S., J. Vet. Med. Sci., 53, 779-787 (1991).

20) Webb N. E., Bull. Parent. Drug Assoc., 30, 180-184 (1976).

21) Sheiner L. B., Stanski D. R., Vozeh S., Miller R. D., Ham J., Clin. Pharmacol. Ther., 25, 358-371 (1979).

22) Yamaoka K., Nakagawa T., J. Pharmacobio-Dyn., 6, 595-606 (1983).

23) Esumi Y., personal communication (1994)

24) Suhihara N., Furuno K., Kita K., Murakami T., Yata N., Biol. Pharm. Bull., 16, 63-67 (1993).

25) Kay G. N., Plumb V. J., Arciniegas J. G., Henthorn R. W., Waldo A. L., J. Am. Coll. Cardiol, 2, 806-817 (1983).

26) Podrid P. J., Am. J. Cardiol., 65, 33E-44E (1990).

27) Bazett H. C., Heart, 7, 353-370 (1920).

28) Hodges M., Salerno D., Erlien D., J. Am. Coll. Cardiol., 1, 694 (1983).

29) Keren A., Tzivoni D., Gavish D., Levi J., Gottlieb S., Benhorin J., Stern S., Circulation, 64, 1167-1174 (1981)

30) Todt H., Zojer N., Raberger G., Br. J. Pharmacol., 110, 145-150 (1993).

31) Zehender M., Hohnloser S., Just H., Cardiovasc. Drugs Ther., 5,
515-530 (1991).

32) Task Force of The Working Group on Arrhythmia of the European Society of Cardiology, Circulation, 84, 1831-1851 (1991).

33) Sanguinetti M. C., Jurkiewicz N. K., J. Gen. Physiol., 96, 195-215 (1990).

34) Wallace A. A., Stupienski R. F., III, Brookes L. M., Selnick H. G., Claremon D. A., Lynch J. J., Jr., J. Cardiovasc. Pharmacol., 18, 687-695 (1991).

35) Rees S. A., Curtis M. J., Circulation, 87, 1979-1989 (1993).

36) Rees S. A., Tsuchihashi K., Hearse D. J., Curtis M. J., J. Cardiovasc. Pharmacol., 22, 343-349 (1993).

37) Salata J. J., Jurkiewicz N. K., Wallace A. A., Stupienski R. F., III, Guinosso P. J., Jr., Lynch J. J., Jr., Circ. Res., 76, 110-119 (1995).

38) Crumb W. J., Jr., Brown A. M., Circulation, 88 (suppl. I), I-230 (1993).

39) Slawsky M. T., Castle N. A., J. Pharmacol. Exp. Ther., 269, 66-74 (1994).

40) Leeson G. A., Chan K. Y., Knapp W. C., Biedenbach G. S., Wright A. J., Okerholm R. A., Arzneim.-Forsch./Drug Res., 32, 1173-1178 (1982). 